\title{
Oestrogens improve human pancreatic islet transplantation in a mouse model of insulin deficient diabetes
}

\author{
S. Liu • G. Kilic • M. S. Meyers • G. Navarro • Y. Wang • \\ J. Oberholzer $\cdot$ F. Mauvais-Jarvis
}

Received: 21 August 2012 / Accepted: 12 October 2012 / Published online: 7 November 2012

(C) The Author(s) 2012. This article is published with open access at Springerlink.com

\begin{abstract}
Aims/hypothesis Pancreatic islet transplantation (PIT) offers a physiological treatment for type 1 diabetes, but the failure of islet engraftment hinders its application. The female hormone $17 \beta$-oestradiol (E2) favours islet survival and stimulates angiogenesis, raising the possibility that E2 may enhance islet engraftment following PIT.

Methods To explore this hypothesis, we used an insulindeficient model with xenotransplantation of a marginal dose of human islets in nude mice rendered diabetic with streptozotocin. This was followed by 4 weeks of treatment with vehicle, $\mathrm{E} 2$, the non-feminising oestrogen $17 \alpha$-oestradiol (17 $\alpha$-E2), the oestrogen receptor (ER) $\alpha$ agonist propyl-pyrazole-triol
\end{abstract}

S. Liu and G. Kilic contributed equally to this work.

Electronic supplementary material The online version of this article (doi:10.1007/s00125-012-2764-1) contains peer-reviewed but unedited supplementary material, which is available to authorised users.

S. Liu · G. Kilic $\cdot$ M. S. Meyers $\cdot$ G. Navarro $\cdot$

F. Mauvais-Jarvis $(\bowtie)$

Department of Medicine, Division of Endocrinology, Metabolism

and Molecular Medicine, Northwestern University Feinberg

School of Medicine,

303 East Chicago Avenue, Tarry 15-761,

Chicago, IL 60611, USA

e-mail: f-mauvais-jarvis@northwestern.edu

\section{Y. Wang $\cdot$ J. Oberholzer}

Department of Surgery, Division of Transplant Surgery,

University of Illinois at Chicago,

Chicago, IL, USA

\section{F. Mauvais-Jarvis}

Northwestern Comprehensive Center on Obesity,

Northwestern University Feinberg School of Medicine,

Chicago, IL, USA

\section{Present Address:}

S. Liu

Diabetes Institute, the First Affiliated Hospital of Xiamen

University,

Xiamen, China
(PPT), the ER $\beta$ agonist diarylpropionitrile (DPN) or the G protein-coupled oestrogen receptor (GPER) agonist G1.

Results Treatment with E2, $17 \alpha$-E2, PPT, DPN or G1 acutely improved blood glucose and eventually promoted islet engraftment, thus reversing diabetes. The effects of E2 were retained in the presence of immunosuppression and persisted after discontinuation of E2 treatment. E2 produced an acute decrease in graft hypoxic damage and suppressed beta cell apoptosis. E2 also acutely suppressed hyperglucagonaemia without altering insulin secretion, leading to normalisation of blood glucose.

Conclusions/interpretation During PIT, E2 synergistic actions contribute to enhancing human islet-graft survival, revascularisation and functional mass. This study identifies E2 as a short-term treatment to improve PIT.

Keywords Diabetes · Engraftment · Glucagon · Islets · Oestrogen $\cdot$ Survival $\cdot$ Transplantation

$\begin{array}{ll}\text { Abbreviations } \\ 17 \alpha \text {-E2 } & 17 \alpha \text {-Oestradiol } \\ \text { DPN } & \text { Diarylpropionitrile } \\ \text { E2 } & 17 \beta \text {-Oestradiol } \\ \text { ER } & \text { Oestrogen receptor } \\ \text { GPER } & \text { G protein-coupled oestrogen receptor } \\ \text { IEQ } & \text { Islet equivalents } \\ \text { JDRF } & \text { Juvenile Diabetes Research Foundation } \\ \text { PIT } & \text { Pancreatic islet transplantation } \\ \text { PPT } & \text { Propyl-pyrazole-triol } \\ \text { STZ } & \text { Streptozotocin } \\ \text { TBARS } & \text { Thiobarbituric acid reactive substances }\end{array}$

\section{Introduction}

Replacing insulin-producing beta cells by human pancreatic islet transplantation (PIT) offers a physiological therapeutic 
approach for type 1 diabetes. PIT benefits recipients in a way that insulin therapy can never achieve [1-3]. Currently, most immunosuppressed type 1 diabetic recipients of human islets allotransplant [3, 4] can successfully attain insulin independence and protection from hypoglycaemia at 1 year. However, there are critical limitations to the widespread application of PIT. First, procuring sufficient islet yield requires several deceased human donors and novel strategies are needed to achieve insulin independence with fewer islets [4]. Evidence suggests that as little as $20 \%$ of the islets within a pancreas are required to maintain euglycaemia [5]. Still, the islets of one or two pancreases are needed to reverse diabetes following PIT, suggesting that a significant portion of the transplanted islets are destroyed or become non-functional. This early islet loss is believed to represent up to $70 \%$ of the transplanted islet mass [6-8]. The transplanted islets are avascular, and islet revascularisation takes 2-3 weeks to complete. During that period, the islets are vulnerable to hypoxic stress and may be destroyed before revascularisation and engraftment occur $[9,10]$. Thus, in the immediate post-transplant period, apoptosis and failure of vascular engraftment pose a challenging problem. We must explore new therapeutic approaches promoting islet survival and revascularisation to enhance islet engraftment.

Recently, the female hormone, $17 \beta$-oestradiol (E2) has been shown to protect mouse and human islets from apoptosis induced by multiple injuries and to stimulate insulin biosynthesis via oestrogen receptors (ERs) present in beta cells [11-18]. E2 also stimulates endometrial angiogenesis and promotes endothelial cell recovery after injury [19-23]. Together, these findings raise the prospect that E2 may be applied to improve islet functional mass and revascularisation during PIT. Here, we used an insulin-deficient mouse model with xenotransplantation of a marginal dose of human islets to test the hypothesis that oestrogens improve islet engraftment during PIT.

\section{Methods}

Animals and the induction of experimental diabetes Diabetes was induced in 10-week-old male nude mice (C57BL/6; Harlan Laboratories, Indianapolis, IN, USA) or male mice null for $E r \alpha$ [24] by a single i.p. injection of $200 \mathrm{mg} / \mathrm{kg}$ streptozotocin (STZ; Sigma Aldrich, St Louis, MO, USA). Blood glucose was monitored with a One Touch Ultra Glucose Monitor (LifeScan, Milpitas, CA, USA). Mice with fed blood glucose exceeding $20.8 \mathrm{mmol} / 1$ were used as recipients. All animal experiments were approved by Northwestern University Animal Care and Use Committee.

Human islet transplantation and in vivo oestrogen treatment Human islets were obtained through the Integrated Islet
Distribution Program and cultured for $48 \mathrm{~h}$ in phenol-redfree CMRL-1066 medium (Sigma Aldrich) containing 10\% (vol./vol.) charcoal-stripped FBS (Gemini Bio, West Sacramento, CA, USA). For in vivo treatment, E2, $17 \alpha$-oestradiol (17 $\alpha$-E2) and G1 (0.18 mg/pellet), propyl-pyrazole-triol (PPT) and diarylpropionitrile (DPN) (3.6 mg/pellet) 60day-release pellets (Innovative Research of America, Sarasota, FL, USA) were implanted subcutaneously immediately before islet transplantation. The dose of E2 was chosen to obtain serum concentrations within physiological limits (ranging from oestrus to pregnancy). The doses of $17 \alpha$-E2 and G1, PPT and DPN were chosen according to the affinity of each agonist for its ER to achieve similar activation of ERs as caused by E2. A marginal dose of 1,000 islet equivalents (IEQ) of human islets were transplanted under the kidney capsule of recipient mice.

Immunosuppression Immunosuppression was achieved as described in the Edmonton protocol, following adaptation to the mouse $[1,25]$. Sirolimus (rapamycin; LC Laboratories, Woburn, MA, USA) was administered via i.p. injection every other day at the dose of $0.1 \mathrm{mg} / \mathrm{kg}$ for 4 weeks, starting from the day of islet transplantation. Tacrolimus (FK506; Cayman, Ann Arbor, MI, USA) was administered i.p. daily at $1 \mathrm{mg} / \mathrm{kg}$, starting on the day of islet transplantation. Control animals received daily vehicle injections.

Immunohistochemistry Kidneys bearing islet grafts were fixed overnight in $4 \%$ (wt/vol) paraformaldehyde at $4{ }^{\circ} \mathrm{C}$. The tissues were immersed in 30\% (wt/vol) sucrose and embedded in tissue-freezing medium (Tissue-Tek; Sakura Finetek, Torrance, CA, USA). Sections, 5-10 $\mu \mathrm{m}$, were mounted on charged slides. For immunohistochemical studies, the following primary antibodies were used: guinea pig anti-human insulin (1:1,000; Linco Research, Saint Charles, MO, USA); rat anti-mouse CD31 (1:400; BD Biosciences, San Jose, CA, USA); rabbit anti-mouse Ki67 (1:400; Novocastra, Newcastle Upon Tyne, UK); rat anti-mouse F4/80 (1:200; AbD Serotec, Raleigh, NC, USA); mouse anti-ER $\alpha$ (1D5; 1:100; Zymed Laboratories, South San Francisco, CA, USA); and goat anti-ER $\beta$ (Y-19; 1:100; Santa Cruz Biotechnology, Santa Cruz, CA, USA). The secondary antibodies were: Cy3-conjugated donkey anti-guinea pig; Cy3conjugated goat anti-rat; biotinylated goat anti-rat; FITCconjugated goat anti-rat; and FITC-conjugated donkey antirabbit (Jackson ImmunoResearch Laboratories, West Grove, PA, USA). Biotinylated goat anti-rat was visualised using the Vectastain Elite ABC kit (Vector Laboratories, Burlingame, CA, USA). For staining with $\operatorname{ER} \alpha$ and $\operatorname{ER} \beta$, the Alexa 568 tyramide signal amplification kit (Molecular Probes, Eugene, OR, USA) was used. For nuclear staining, the sections were incubated with DAPI (Molecular Probes, Eugene, OR, USA). Images were obtained with a Nikon 
Eclipse E400 microscope (Nikon Instruments, Melville, New York, USA) or TissueGnostics High Throughput Imaging System (TissueGnostics, Vienna, Austria).

Measurement of apoptosis using TUNEL assay Apoptotic cells were detected by TUNEL assay using a fluorescein in situ cell death detection kit (Roche, Indianapolis, IN, USA) 1 day after transplantation. Frozen tissue sections, $5 \mu \mathrm{m}$, were fixed at room temperature for $1 \mathrm{~h}$ in $4 \%$ (vol./vol.) PFA in PBS, pH7.4. Samples were washed in PBS for $30 \mathrm{~min}$. Following the manufacturer's instructions, sections were permeabilised, washed, labelled, incubated and analysed. Sections were subsequently stained with guinea pig antihuman insulin as a primary antibody $(1: 1,000)$ and Cy3conjugated donkey anti-guinea pig as a secondary antibody. Images were obtained with a Nikon Eclipse E400 microscope.

Measurement of oxygenation in transplanted islet graft Islet oxygenation was investigated in the transplants, 1 day posttransplantation [26]. Pimonidazole hydrochloride (hpi Hydroxyprobe-1; Omni Kit, Burlington, MA, USA) $(60 \mathrm{mg} / \mathrm{kg})$ was injected i.p. Mice were killed $3 \mathrm{~h}$ later, and their kidney containing the islet graft was processed for immunohistochemistry. Rabbit anti-pimonidazole antibody (hpi Hydroxyprobe-1; Omni Kit) was used to visualise pimonidazole hydrochloride accumulation in hypoxic cells of the graft.

Morphometric analysis Kidneys bearing islet grafts were sectioned in $10 \mu \mathrm{m}$ thickness and four sections per tissue were randomly chosen for morphometric analysis. Antihuman-insulin and anti-mouse-CD31 antibodies were used to visualise beta cells and blood vessels, respectively. Morphometric analysis was conducted using the Image J $1.37 \mathrm{v}$ (rsb.info.nih.gov/ij/) program. In islet transplants, the beta cell area was calculated by dividing the insulin-positive area by the graft area. Blood vessel density was calculated by dividing the mouse-CD31-positive area by the graft area [27]. The demarcation of an islet graft was considered to be the parenchyma of the surrounding kidney as described [10].

Hormone and thiobarbituric acid reactive substances assays Human insulin and mouse glucagon was measured in serum by ELISA and RIA, respectively (Linco, St Charles, MO, USA). Systemic oxidative stress was assessed by measuring the concentration of thiobarbituric acid reactive substances (TBARS) in plasma (Cayman) and kidney homogenates (ZeptoMetrix, Franklin, MA, USA) [28].

Lectin infusion Biotinylated tomato lectin (Vector Laboratories) was injected into the tail vein $(200 \mu \mathrm{g})$ and allowed to circulate for $5 \mathrm{~min}$ before the mice were killed. The kidneys bearing the islet grafts were removed and prepared for histological study. Lectin staining was visualised using the Vectastain Elite ABC kit (Vector Laboratories). Functional blood vessel density was obtained by dividing the lectin-positive area by the graft area.

Statistical analysis Data are presented as mean \pm SEM unless otherwise stated. For the rodent study, data were analysed by either the unpaired Student's $t$ test or one-way ANOVA. A value of $p<0.05$ was considered statistically significant.

\section{Results}

Oestrogens ameliorate diabetes We investigated the therapeutic action of oestrogens on islet transplantation outcomes. We used male immunodeficient nude mice rendered totally insulin deficient by injection of a single high dose of STZ $(200 \mathrm{mg} / \mathrm{kg})$. In these mice, we performed either sham transplantation or xenotransplantation of a marginal dose of human islets (1,000 IEQ) under the renal capsule (PIT). This was followed by treatment with vehicle or E2, leading to serum concentrations within the physiological range (E2 levels: vehicle $68.49 \pm 25.5 \mathrm{pg} / \mathrm{ml}$; E2 injection $321.93 \pm 77.15 \mathrm{pg} / \mathrm{ml}$ ), the non-feminising E2 stereoisomer 17 $\alpha$-E2 [29], the ER $\alpha$-selective agonist PPT [30], the ER $\beta$-selective agonist DPN [31] and the G proteincoupled oestrogen receptor (GPER) agonist G1 [32]. Following PIT or sham transplantation, blood glucose was monitored for 3 weeks. PIT mice treated with vehicle remained hyperglycaemic, but conversely, PIT mice treated with E2, $17 \alpha$-E2, PPT, DPN or G1 showed a dramatic improvement in blood glucose (Fig. 1a-f) starting 1 day after transplantation. In sham-operated diabetic mice, E2, $17 \alpha$-E2, PPT, DPN and G1 treatment had no effect on blood glucose (Fig. 1a-f) or body weight (electronic supplementary material [ESM] Fig. 1) compared with vehicle. This finding demonstrated that the improvement in blood glucose by ER agonists required the presence of transplanted human islets. A similar protection of human PIT was observed in female nude mice treated with E2 (ESM Fig. 2), demonstrating that E2 protection is not sex specific. Thus, we performed the rest of the study in male mice.

Oestrogens enhance islet engraftment At 4 weeks after PIT, mice treated with E2, $17 \alpha-\mathrm{E} 2$, PPT, DPN or G1 showed protection of islet-graft beta cell mass (Fig. 2a, b) associated with a rise in human serum insulin concentrations compared with vehicle-treated PIT mice (Fig. 2c). Insulin response to i.p. arginine was also increased in the E2-compared with the vehicle-treated mice (Fig. 2d, e). Additionally, the endogenous pancreatic beta cell mass of STZ-treated PIT recipient mice was efficiently reduced and unaffected by ER agonist 
Fig. 1 Oestrogens ameliorate diabetes after PIT. Effect of (a) E2, (b) $17 \alpha$-E2, (c) PPT, (d) DPN and (e) G1 on blood glucose after PIT. (f) Blood glucose AUC was calculated from (a-e). Values represent the mean \pm SEM, $n=4-18$ /group. ${ }^{*} p<0.05,{ }^{* *} p<0.01$. AS, after STZ; BS, before STZ; V, vehicle
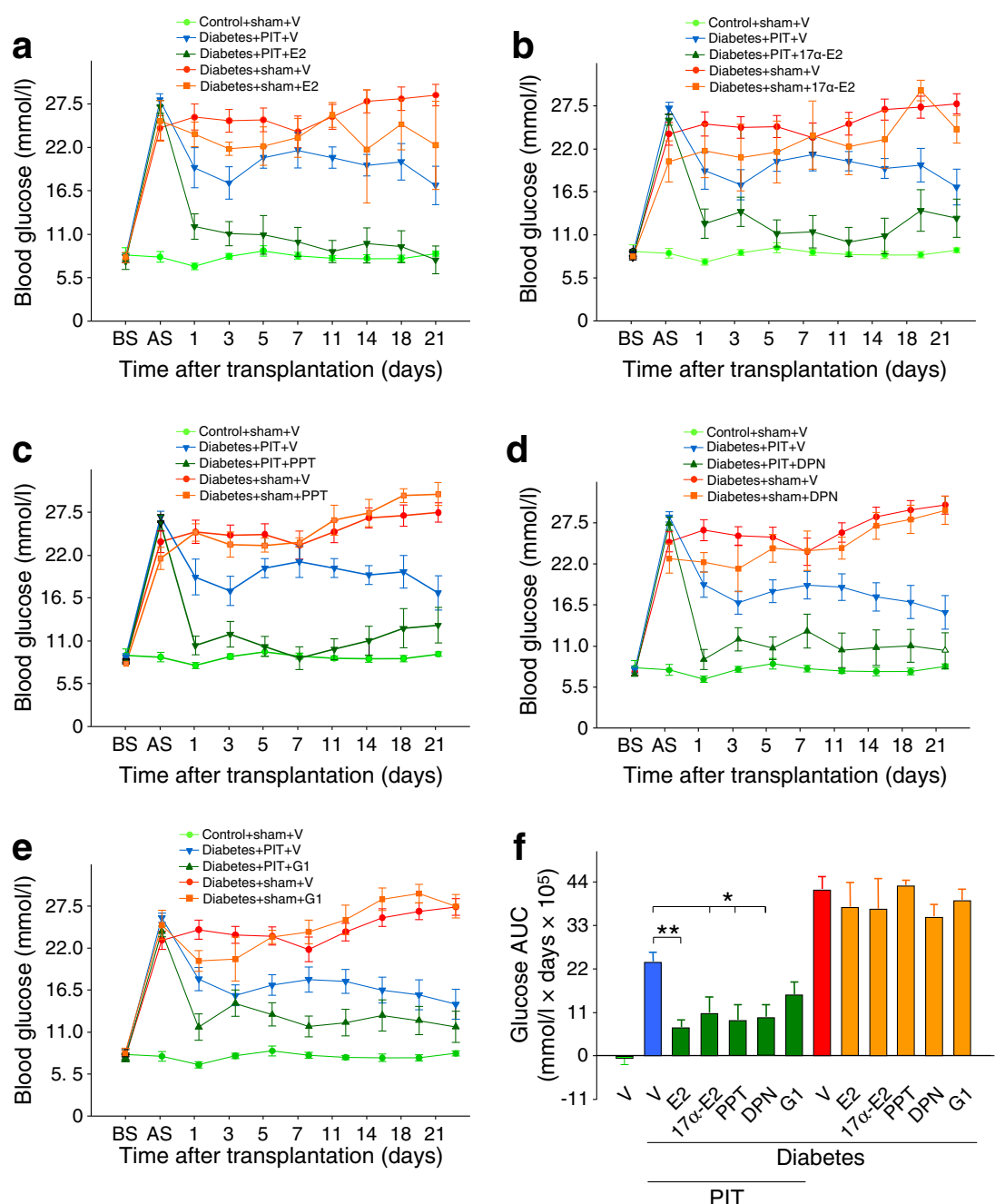

treatments (ESM Fig. 3). Thus, activation of ER $\alpha, E R \beta$ and GPER with oestrogens preserves functional islet mass and reverses diabetes after PIT.

We next quantified the endothelial cell area in islet grafts using the mouse endothelial cell marker CD31. At 4 weeks after PIT, mice treated with E2, $17 \alpha$-E2, PPT or DPN showed an improvement in islet revascularisation compared with vehicle-treated mice (Fig. $2 \mathrm{f}, \mathrm{g}$ ). Conversely, the mice treated with G1 did not show any improvement compared with controls (Fig. 2f, g). To determine the functionality of the E2-induced reconstructed islet vasculature network, we applied in vivo staining for lectin - a commonly used marker of vessel functionality [33] - to a group of mice treated with vehicle or E2. We detected increased lectin staining in E2-treated mice compared with vehicle-treated mice (Fig. 2h, i), demonstrating that E2 increased functional vessel density in the transplanted islets. While the contribution of endothelial cells from freshly isolated donor islets to the formation of functional vessels within islet grafts has been demonstrated [33,34], cultured islets lose most of their endothelial cell populations within 3 days of culture [34].
We thus examined whether E2 treatment could preserve the intra-islet endothelial cell population in freshly isolated mouse islets. Consistent with a previous report [34], we observed that the islet endothelial cell number decreased within 1 day of culture and totally disappeared after 3 days. However, we observed no beneficial effect of E2 treatment on the maintenance of intra-islet endothelial cell population (ESM Fig. 4). As E2 favours islet survival, we tested whether in vitro E2 treatment of human islets prior to PIT could improve PIT outcome using the same model system. We observed that E2 treatment of cultured human islets prior to PIT had no significant effect on subsequent glycaemic control either alone or in association with in vivo E2 treatment (ESM Fig. 5).

Improvement of islet engraftment persists in the presence of immunosuppression and after discontinuation of E2 treatment The Edmonton protocol has facilitated human islet transplantation by using non-steroidal immunosuppressive treatment such as sirolimus (rapamycin) and tacrolimus (FK-506) [1, 3]. However, these regimens undermine 
a

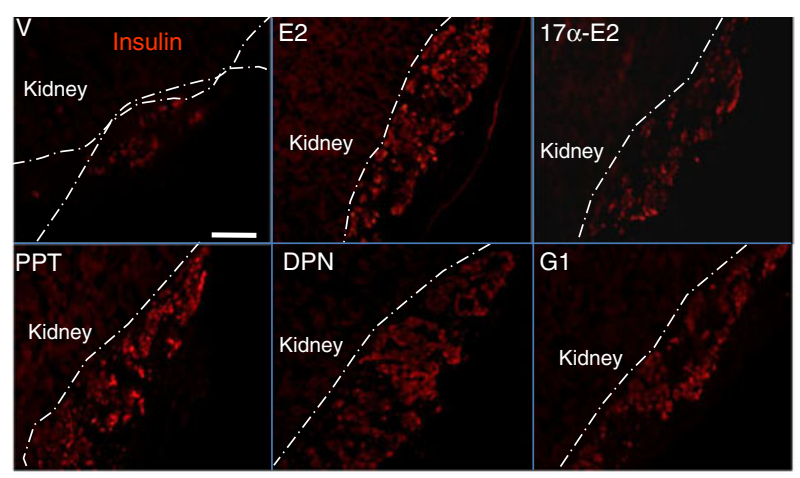

f

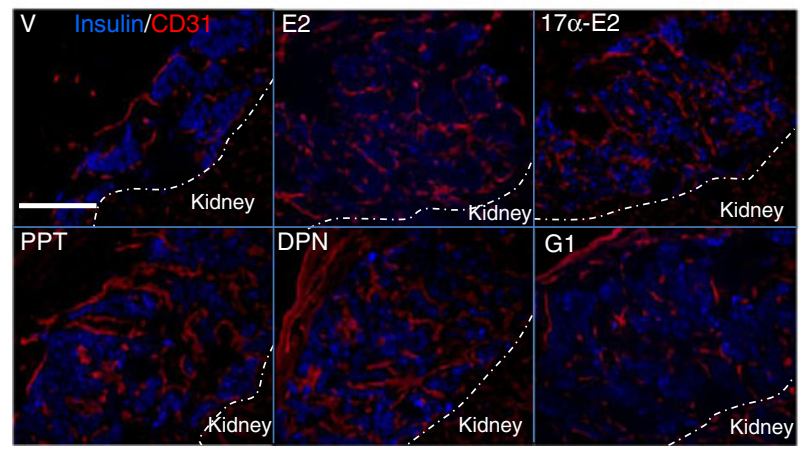

Fig. 2 Oestrogens improve islet engraftment after PIT. (a) Representative sections showing immunofluorescence staining for insulinpositive cells in islet grafts. (b) Quantification of graft beta cell area (insulin-positive area/total graft area). (c) Ratio of random-fed insulin (pmol/l)/glucose $(\mathrm{mmol} / \mathrm{l})$ was used as an index of insulin production. (d) Insulin response to L-arginine (ASIS) (black, vehicle; white, E2) following i.p. L-arginine injection $(3 \mathrm{~g} / \mathrm{kg})$. (e) AUC for ASIS from (d).

angiogenesis and represent a significant obstacle to islet engraftment $[35,36]$. To determine the persistence of E2 improvement of islet engraftment after PIT in the presence of immunosuppression, we treated a group of mice with sirolimus and tacrolimus for 4 weeks in the presence of vehicle or E2. The treatments did not alter E2-induced improvement of glycaemic control and islet revascularisation (Fig. 3a, b), demonstrating that E2 improves PIT in the presence of immunosuppression. As chronic E2 treatment following islet transplantation is not suitable in the clinical setting, we sought to determine whether glycaemic control could be sustained after E2 discontinuation. We followed a group of PIT mice for 112 days, during which time we maintained the E2 treatment for the first 60 days. Our results show that E2 efficacy on PIT outcome, assessed by normalisation of blood glucose, lasted for 50 days after E2 discontinuation (Fig. $3 \mathrm{c}$ ). These findings suggest that transient E2 treatment has induced a permanent improvement in functional islet mass and engraftment. b

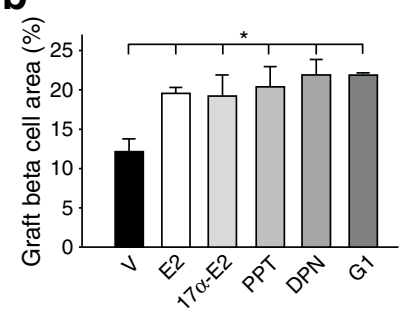

d

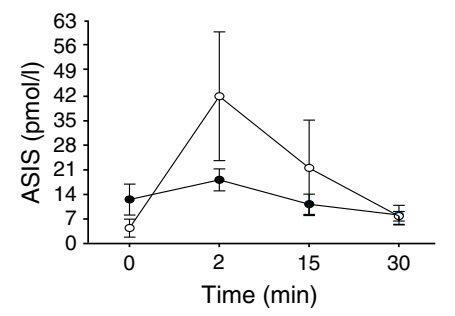

e
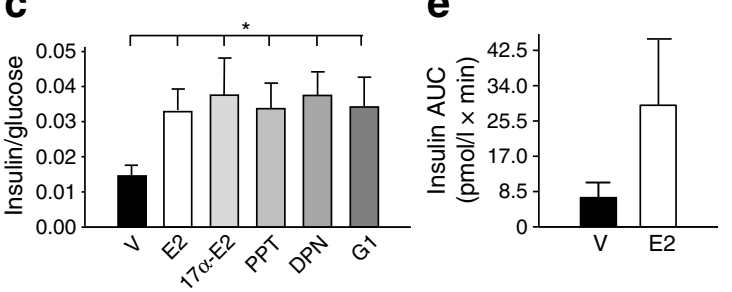

g

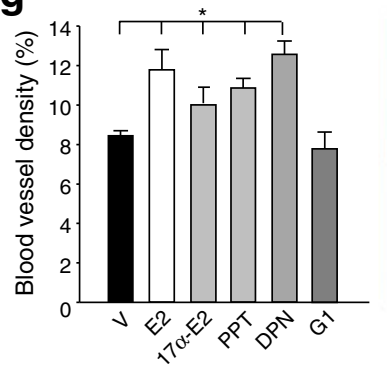

h
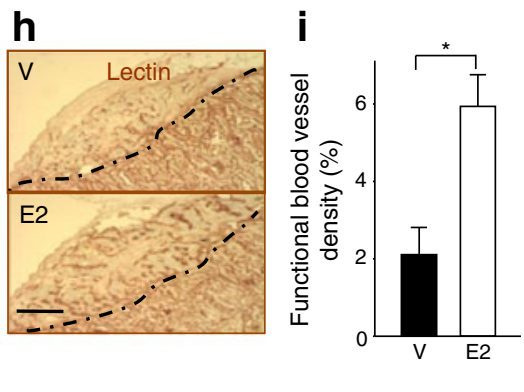

(f) Representative sections of mouse CD31 immunofluorescence staining in islet grafts. (g) Quantification of graft blood vessel density (CD31-positive area/graft area). (h) Representative sections showing lectin staining in islet grafts. (i) Quantification of graft functional blood vessel density (lectin-positive area/graft area). In (a) and (f) the cell nuclei were stained with DAPI (blue). Values represent the mean \pm SEM, $n=3-9 /$ group. ${ }^{*} p<0.05$. Scale bars, $100 \mu \mathrm{m}$. V, vehicle

E2 acutely improves islet-graft hypoxia The acute correction of hyperglycaemia observed 1 day after transplantation (Fig. 1) - a time when revascularisation has not yet taken place - suggested that oestrogens had acutely improved islet survival and/or function independently from the graft revascularisation. Because the process of islet transplantation elicits an acute inflammatory response, we first looked at whether E2 had acutely suppressed graft inflammation. We observed no difference between the E2- and vehicle-treated groups in graft macrophage infiltration (ESM Fig. 6). E2 improves splanchnic macro- and microcirculation during haemorrhagic shock [37]. A similar improvement in renal cortex microcirculation would improve islet-graft oxygenation, thus improving survival and function at this early stage when islets are not revascularised. To explore this possibility, we quantified graft hypoxia using pimonidazole [26] at 1 day after PIT. We observed a marked decrease in the hypoxic area in E2-treated grafts (Fig. 4a). Hyperglycaemia and hypoxia provoke the formation of oxygen free radicals 
Fig. 3 Improvement of PIT persists in the presence of immunosuppression and after discontinuation of E2 treatment. (a) Line graph showing the effect of E2 on blood glucose in the presence of immunosuppressive treatment (black circles, PIT $+\mathrm{V}$; white circles, PIT+E2; black triangles, PIT+E2+ immunosuppressant), and bar chart showing blood glucose AUC as calculated from the graph. (b)

Quantification of graft blood vessel density (CD31-positive area/graft area) in mice from (a). (c) Blood glucose was measured in vehicle-treated (black circles) and E2-treated (white circles) mice on the indicated days. Values represent the mean \pm SEM, $n=7-9$ /group. ${ }^{*} p<0.05$. AS, after STZ; BS, before STZ; IS, immunosuppressant; V, vehicle a
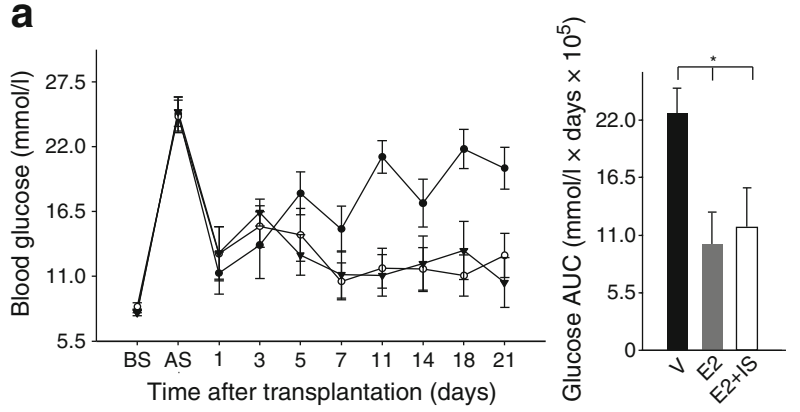

b

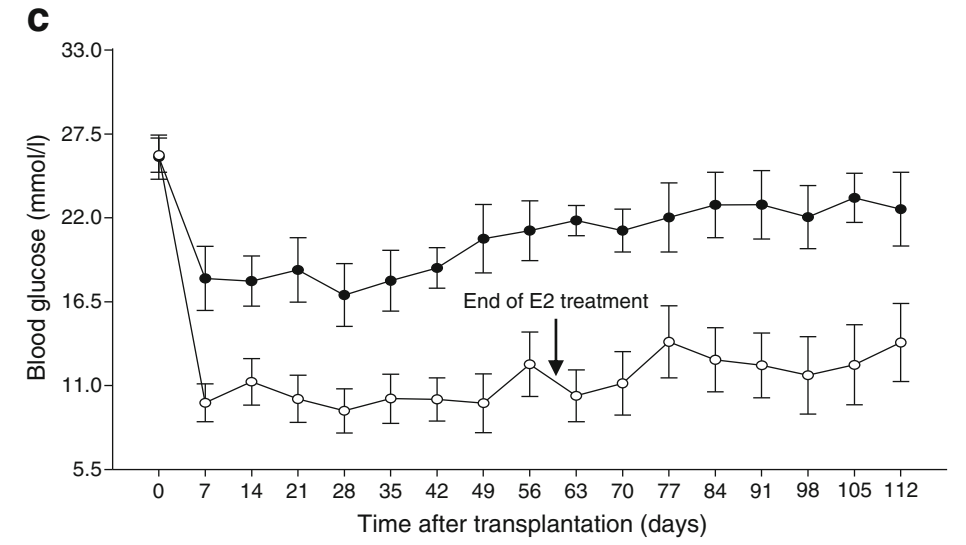

and lipid peroxidation that trigger islet apoptosis. To measure oxidative stress, we quantified lipid peroxidation in serum and kidney tissue adjacent to the graft using the TBARS method [28]. We observed decreased serum and kidney TBARS concentration in E2-treated mice, demonstrating that E2 treatment has improved hypoxic stress in these mice (Fig. 4b, c).

E2 acutely suppresses graft beta cell apoptosis We next studied graft beta cell turnover and function in the early post-transplant period. We observed that E2 treatment acutely suppressed apoptosis (day 1 after PIT; Fig. 5a), without an effect on beta cell proliferation (ESM Fig. 7). This was associated with a greater beta cell graft area (day 3 after PIT; Fig. 5b), suggesting a retained beta cell mass. E2 treatment dramatically improved i.p. glucose tolerance in PIT mice (Fig. 5c) but, surprisingly, despite the retained beta cell area, E2 acute suppression of blood glucose was not associated with increased glucose-stimulated insulin secretion (Fig. 5d) and random-fed insulin concentrations were reduced (Fig. 5e).

PPT acutely suppresses blood glucose in the absence of $E R \alpha$ in the islet graft As E2 suppression of blood glucose was independent from an enhanced insulin secretion from the islet graft, we asked whether this effect required direct activation of ER in the islet graft or ER activation in the recipient tissue (leading to increased insulin sensitivity). To address this issue, we used $\mathrm{ER} \alpha$ as a paradigm of $\mathrm{E} 2$ actions and mice with global null deletion of $\operatorname{Er\alpha }\left(E r \alpha^{-1-}\right.$ mice $)$. We a

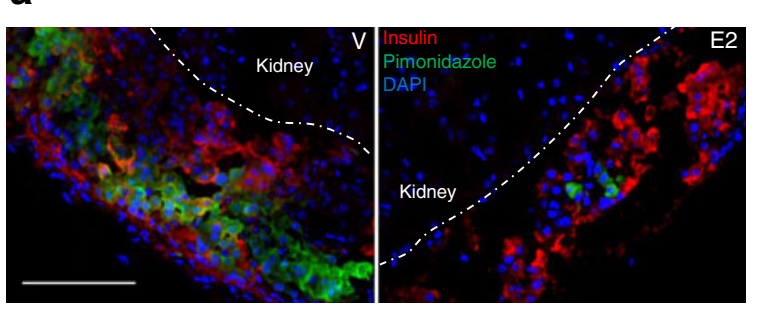

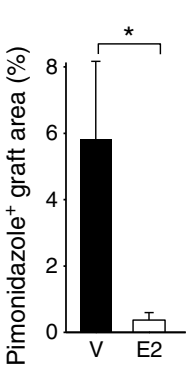
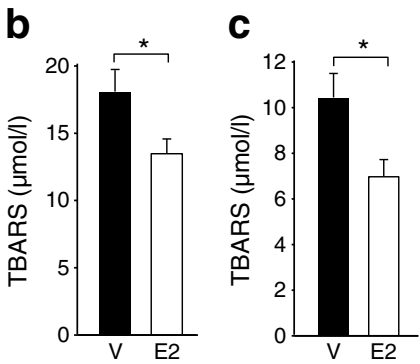

Fig. 4 E2 acutely improves islet-graft hypoxia. (a) Representative pictures of pimonidazole staining (green) in the islet grafts, 1 day after PIT, and bar chart showing pimonidazole-positive area in the graft. In the images, red fluorescence has been used for insulin. The cell nuclei were stained with DAPI (blue). Lipid peroxidation was determined in (b) plasma and in (c) islet-bearing kidney homogenates, 1 day after PIT, by TBARS assay. Values represent the mean \pm SEM, $n=3-8$ / group. ${ }^{*} p<0.05$. Scale bars, $50 \mu \mathrm{m}$. V, vehicle 
Fig. 5 E2 treatment acutely prevents beta cell apoptosis. (a) Representative sections showing immunofluorescence staining for TUNEL-positive (green) and insulin-positive (red) cells in islet grafts, 1 day after PIT. Arrows show TUNEL-positive beta cells. Bar charts show quantification of TUNEL-positive/beta cells (insulin-positive) area in the graft. Scale bar, $25 \mu \mathrm{m}$. (b) Representative sections showing immunofluorescence staining for insulin-positive (red) cells in islet grafts. Bar charts showing the percentage of insulinpositive area in graft. Scale bar $100 \mu \mathrm{m}$. (c) Line graph showing results of i.p. glucose tolerance test ( $2 \mathrm{mg} / \mathrm{kg}$ body weight; black circles, vehicle; white circles, E2), and bar chart with corresponding AUC for glucose. (d) Insulin secretion after i.p. GTT (black circles, vehicle; white circles, E2). (e) Plasma human insulin levels. In (a) and (b) the cell nuclei were stained with DAPI (blue). In (b), (c), (d) and (e) measurements were made on day 3 after PIT. Values represent the mean $\pm \mathrm{SEM}, n=5-11$ /group. ${ }^{*} p<0.05,{ }^{* *} p<0.01$. V, vehicle

Fig. 6 E2 acutely suppresses blood glucose via $\mathrm{ER} \alpha$ activation outside the islet graft. (a) Line graph showing the effect of PPT on blood glucose after transplantation of WT and $\mathrm{ErO}^{-1-}$ mouse islets in WT recipient mice and bar chart showing corresponding glucose AUC. (b) Line graph showing the effect of PPT on blood glucose after transplantation of WT mouse islet in $\mathrm{Er \alpha}^{-1}$ recipient mice (blue, vehicle; green, PPT), and bar chart showing the corresponding blood glucose AUC. Values represent the mean $\pm \mathrm{SEM}$, $n=3-14$ /group. * $p<0.05$.

AS, after STZ; BS, before STZ; $\mathrm{V}$, vehicle
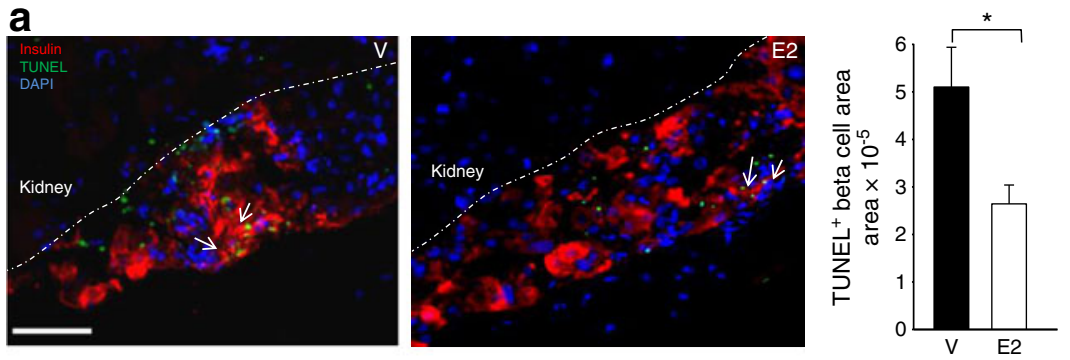

\section{b}
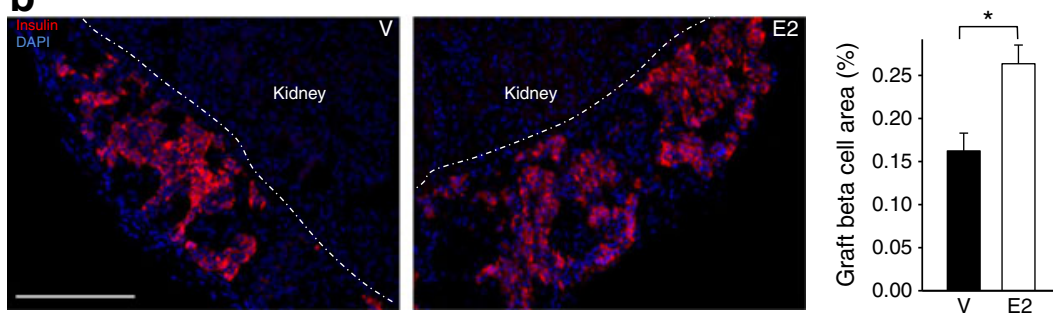

\section{C}
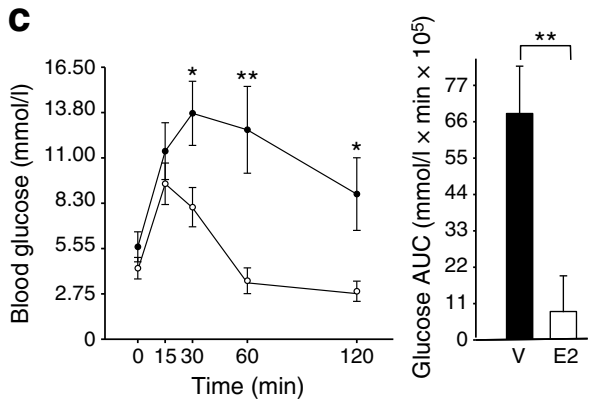

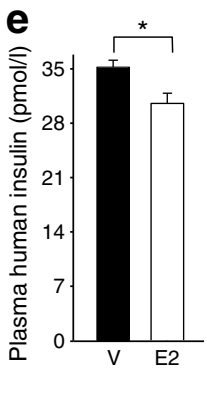

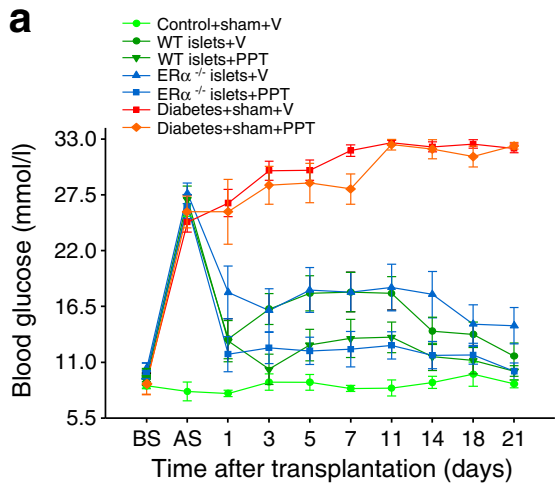

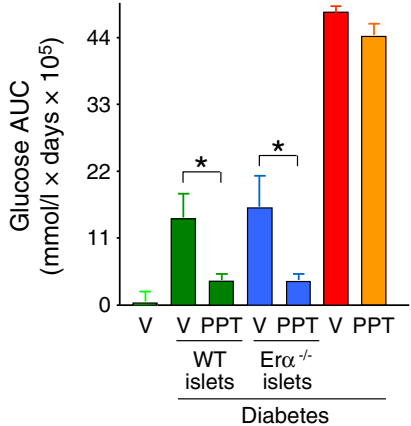

b

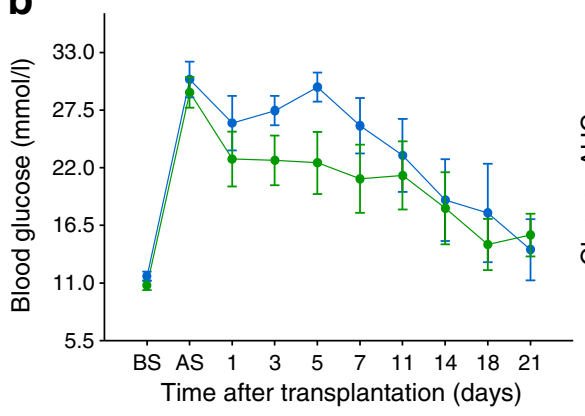

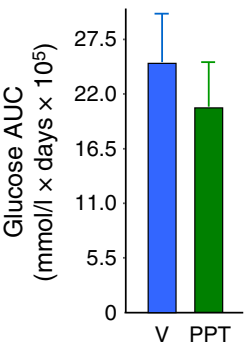


first performed an allotransplantation of a marginal dose of islets (150) isolated from donor littermate wild-type (WT) or $\mathrm{ErO}^{-/-}$mice under the kidney capsule of recipient WT mice. These recipient mice were treated with vehicle or the ER $\alpha$ selective agonist PPT. As expected, WT mice transplanted with WT or $\mathrm{Er \alpha}^{-/-}$islets and treated with vehicle remained hyperglycaemic. However, PPT treatment led to a similar early decrease in blood glucose in WT mice transplanted with WT or $\mathrm{ErQ}^{-/-}$islets, demonstrating that PPT improves PIT in the absence of islet ER $\alpha$ (Fig. 6a). Next, we performed an allotransplantation of a marginal dose of WT islets in recipient $E r \alpha^{-1-}$ mice followed by treatment with vehicle or PPT. Vehicle- and PPT-treated mice showed a similar and minor blood-glucose-lowering effect due to the transplantation of WT islets in $\mathrm{ErO}^{-1-}$ mice. However, PPT treatment did not produce a stronger hypoglycaemic effect than vehicle in these ER $\alpha$-deficient mice. Together, these data demonstrate the requirement of $E R \alpha$ activation in the recipient mouse tissues to acutely suppress blood glucose (Fig. 6b).

E2 acutely suppresses glucagon production That treatment with the ER $\alpha$ agonist PPT produced an acute decrease in blood glucose in the absence of ER $\alpha$ in the islet graft and without an increase in insulin secretion suggests that PPT acts on the host alpha cells to suppress glucagon secretion. Indeed, unsuppressed hyperglucagonaemia plays a major role in hyperglycaemia in all forms of insulin-deficient diabetes $[38,39]$. To address this issue, we looked at the effect of E2 treatment on serum glucagon in the early transplant period. First, we observed that ER $\alpha$ and ER $\beta$ were present in alpha cells from mice and human islets (Fig. 7a-d). In glucagon-secreting INR1G9 cells and $\alpha \mathrm{TC} 6$ cells, the $67 \mathrm{kd}$-long isoform of ER $\alpha$ was produced at a level similar to that in insulin-secreting MIN-6 cells (ESM Fig. 8). In addition, we observed that 1 day after PIT, E2 treatment was associated with a dramatic suppression of serum glucagon compared with vehicle-treated mice in random-fed state ( $-65 \%$, Fig. 7 e), thus providing an explanation for the simultaneous decrease in glucose (Fig. 1a) and insulin levels (Fig. 5e) associated with E2 treatment.

\section{Discussion}

The present study shows that E2, used at physiological concentrations, improves islet engraftment in a sex-nonspecific manner in an insulin-deficient nude mouse model transplanted with a marginal dose of human islets and in the absence of allorejection or autoimmunity recurrence. Several non-exclusive mechanisms could be implicated.

Suppression of hyperglucagonaemia The acute correction of hyperglycaemia and improvement of glucose tolerance a


b
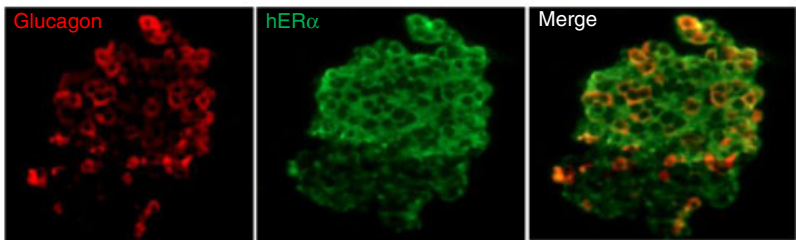

C
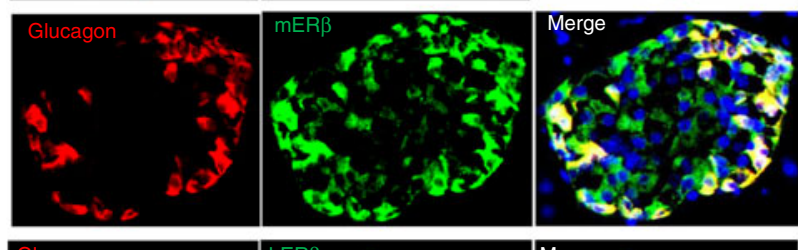

d

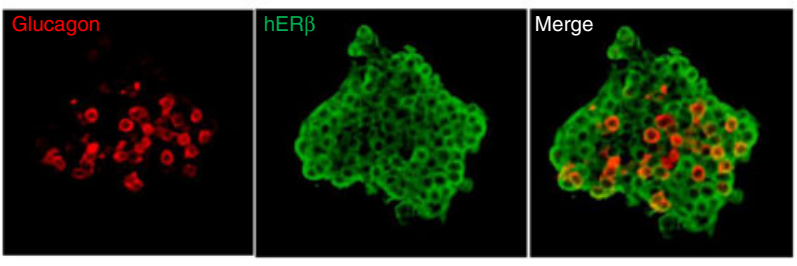

e

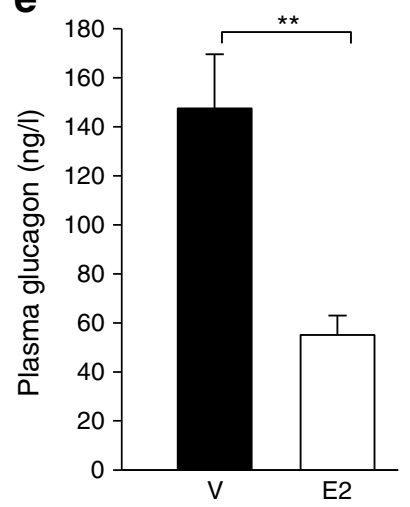

Fig. 7 E2 acutely suppresses hyperglucagonaemia. Representative pictures of islets showing co-localisation of (a) mouse ER $\alpha$, (b) human $\mathrm{ER} \alpha$, (c) mouse $\mathrm{ER} \beta$, and (d) human $\mathrm{ER} \beta$ (green) with alpha cells stained with glucagon (red). In (a) and (c), the cell nuclei were stained with DAPI (blue). (e) Plasma glucagon levels at day 1 after PIT. Values represent the mean \pm SEM, $n=3-5 /$ group. ${ }^{* *} p<0.01$. Scale bar, $25 \mu \mathrm{m}$. $\mathrm{h}$, human; $\mathrm{m}$, mouse; $\mathrm{V}$, vehicle

observed 1 day after transplantation and following E2 treatment occur without an increase in graft insulin secretion. In fact, E2 treatment produces a decrease in fed serum insulin concentrations, suggesting that E2 has improved insulin sensitivity. Indeed, the E2 hypoglycaemic action occurs in the face of better suppression of serum hyperglucagonaemia. This observation suggests that the E2-mediated acute suppression of blood glucose is independent of an improvement in beta cell function; rather, it is dependent on glucagon suppression. This may explain why E2-treated mice 
have suppressed hyperglucagonaemia and lower insulin concentrations, as a decrease in hyperglucagonaemia improves glucagon-induced hepatic insulin resistance. This observation is also consistent with the 'glucagonocentric' vision of diabetes pathophysiology in which glucagon excess, rather than insulin deficiency, is the sine qua non of hyperglycaemia in all forms of diabetes, at least in rodents [40]. Indeed, total insulin deficiency by beta cell destruction in glucagon-receptor-null mice, which are unresponsive to glucagon, does not cause diabetic abnormalities [41]. We observe that ER $\alpha$ and ER $\beta$ are produced in mouse and human alpha cells, further indicating that alpha cells are direct targets of E2 actions. In addition, our experiments suggest that ER $\alpha$ needs to be activated in alpha cells of the host pancreas as the hypoglycaemic effect of an ER $\alpha$ selective agonist is lost when islets from WT mice are transplanted in $\mathrm{Er} \alpha$ null mice (lacking ER $\alpha$ in alpha cells). Accordingly, the ER $\alpha$ agonist can still acutely suppress blood glucose and permanently improve diabetes when $\mathrm{ER} \alpha$-deficient islets are transplanted in WT mice. This demonstrates that $\mathrm{ER} \alpha$ action in graft alpha cells is not necessary to suppress blood glucose. Recently, leptin has been shown to suppress glucagon and correct diabetes in mice, in the absence of insulin [42]. Our results suggest that E2 requires the presence of insulin - or at least functional beta cells - to suppress glucagon as ER agonists have no hypoglycaemic effect in diabetic mice in the absence of transplanted islets. This observation is consistent with the concept that insulin suppresses glucagon secretion from alpha cells via paracrine mechanisms [43] and that insulin signalling in alpha cells is required for this process [44]. Thus, in the alpha cells of diabetic mice E2 may act as an insulin sensitiser in suppressing glucagon production. Additional studies in mice lacking ERs in alpha cells are needed to address this issue.

Protection of functional beta cell mass Oestrogens have acutely improved islet survival following transplantation, as demonstrated by E2-mediated acute suppression of graft apoptotic beta cells. This is the first evidence that E2, used at therapeutic doses, protects human islets from apoptosis in an in vivo diabetic environment. We and others have shown that E2 promotes islet survival in conditions of oxidative stress and pro-inflammatory cytokine injury in culture and in vivo $[11-13,17]$. Higher islet functionality and decreased apoptosis are also observed after transplantation of rat islets recovered from E2-treated brain-dead donors [45]. This antiapoptotic protection probably accounts for the early retention of graft beta cell mass, which persists after 3 weeks of ER agonist treatment. In addition, we believe that E2 antiapoptotic protection is also mediated via activation of ERs in recipient endothelial cells. E2 dilates the mesenteric arteries and increases mesenteric blood flow [46, 47]. E2 also improves splanchnic circulation during haemorrhagic shock, which increases oxygenation [37]. We observed that E2 acutely and dramatically improved islet-graft hypoxia, which is associated with decreased systemic and kidney oxidative damage. This protection of islet oxygenation is
Fig. 8 Schematic representation of the proposed mechanisms of E2 improvement of islet engraftment. E2 exhibits acute actions in recipient endothelial cells, decreasing islet-graft hypoxic stress, that synergise with E2 acute action in graft beta cells to prevent apoptosis. In addition, E2 exhibits acute actions in recipient alpha cells suppressing hyperglucagonaemia and hyperglycaemia. These acute actions help retain the initial beta cell mass. E2 also exhibits late actions on graft endothelial cells to improve revascularisation. These acute and late E2 actions concur to promote islet engraftment and maintenance of functional beta cell mass

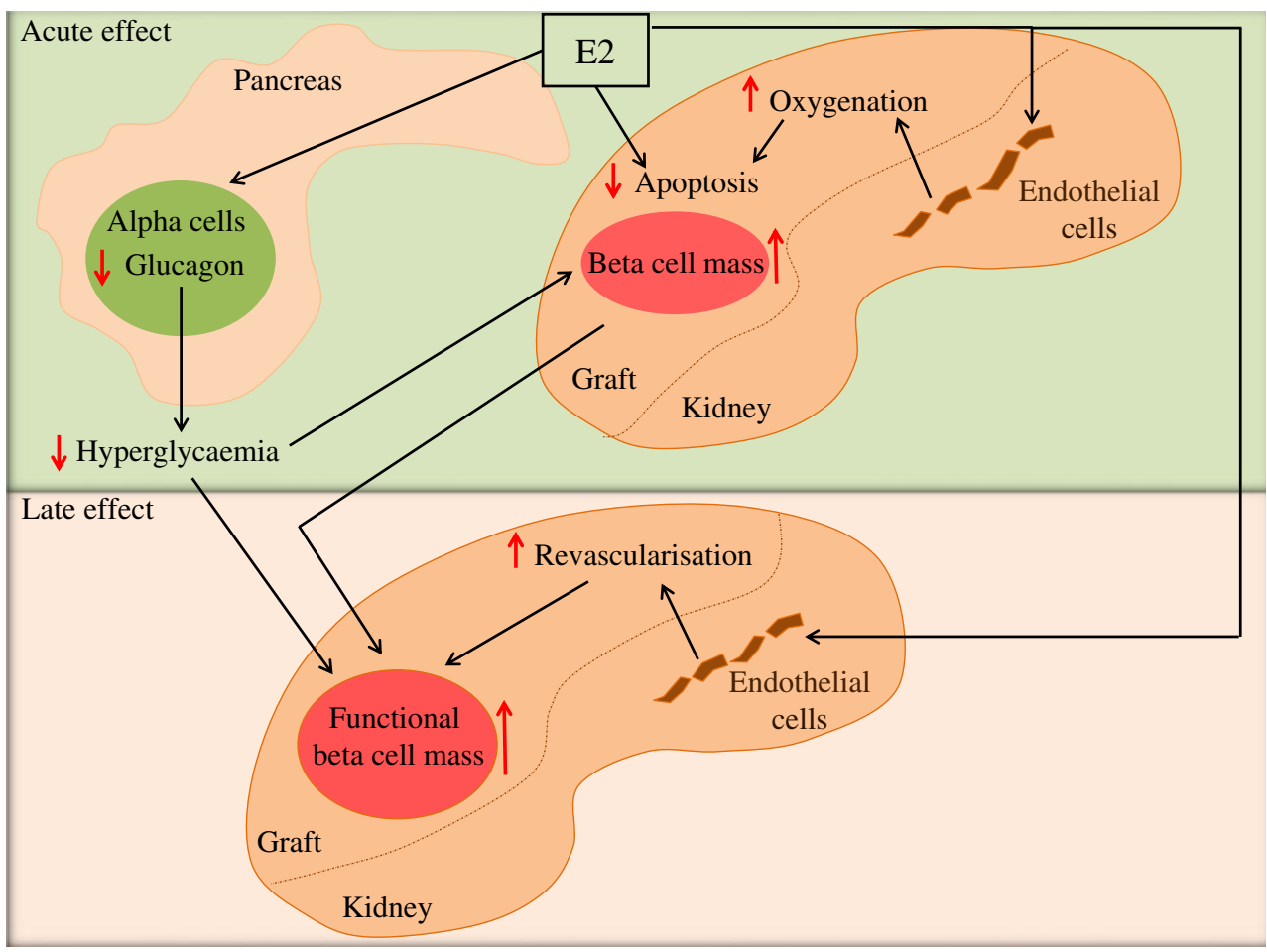


probably instrumental in E2 acute anti-apoptotic protection as, following PIT, hypoxic stress is a critical factor in the early loss of islet mass [8-10]. Initially, E2-treated graft beta cells are non-functional and show no insulin-secretory response to the glucose challenge, probably as a result of hyperglycaemia-induced glucose desensitisation and/or lack of islet vascularisation. However, following 3 weeks of normoglycaemia, PIT mice treated with ER agonists show a restoration of beta cell function. Thus, E2 acute normalisation of blood glucose, via suppression of hyperglucagonaemia, has favoured the subsequent restoration of beta cell function following correction of glucose desensitisation.

Action on recipient endothelial cells Apart from E2mediated acute improvement of islet-graft oxygenation, the likely action of oestrogens involves the enhancement of islet revascularisation through action on recipient endothelial cells, as E2 is a potent angiogenic factor in the endometrium and following vascular injury [22, 23]. Accordingly, E2 increases the functional blood vessel density of the human islet graft. More importantly, immunosuppression with sirolimus and tacrolimus typically inhibits islet revascularisation and engraftment. Yet E2 stimulation of revascularisation persists in the presence of this immunosuppression regimen. Furthermore, after discontinuation of E2 treatment the correction of diabetes endures, demonstrating that $\mathrm{E} 2$ has induced a stable engraftment. E2 treatment promotes revascularisation of the transplanted human islets through ERs on the endothelial cell from the recipient kidney cortex and without the participation of endothelial cells from the human graft, as these cells had disappeared at the time of transplantation. However, G1, which exhibits potent anti-apoptotic action in human islets [13], improves PIT outcome without enhancing graft revascularisation, suggesting that the acute hypoglycaemic and anti-apoptotic effects of oestrogens are more important to the engraftment process than the moderate increase in revascularisation.

Thus, the synergistic actions of E2 on ERs in recipient alpha cells, endothelial cells and graft beta cells leading, respectively, to the suppression of hyperglucagonaemia and hyperglycaemia, the protection from islet-graft hypoxia, oxidative stress and apoptosis and ultimately to revascularisation of the graft, have concurred to promote islet engraftment and maintenance of beta cell functional mass. A summary of the proposed mechanisms of E2 action is shown in Fig. 8.

Our findings have direct therapeutic implications for PIT in type 1 diabetes. Although long-term E2 treatment following PIT is not suitable because of the risk of cancer, conversely, transient E2 treatment represents a safe and immediately available alternative to improve PIT in women. Indeed, fertile women with type 1 diabetes show E2 deficiency compared with healthy women [48]. Therefore, women with type 1 diabetes undergoing islet transplantation have lost their endogenous E2 protection and could benefit from short-term oestrogen supplementation using therapeutic doses. Furthermore, $17 \alpha$-E2, which is endogenous in humans, has few of the biological effects associated with the female hormone activity and may be a candidate for sexneutral therapy in PIT.

In conclusion, E2 enhances islet engraftment after PIT. As oestrogens are approved by the Food and Drug Administration, further testing in women with the addition of oestrogens to the Edmonton protocol should be considered. This could provide an immediate therapeutic alternative to improve PIT and achieve insulin independence with fewer islets, long before other surrogate islet beta cell sources or beta cell regeneration therapy can be developed.

Acknowledgements We are grateful to B. Hering from the University of Minnesota for helpful discussion and to M. Brissova and A. Powers from Vanderbilt University for providing protocol and advice on in vivo lectin infusion. We acknowledge the Integrated Islet Distribution Program (IIDP) funded by the National Institute of Diabetes and Digestive and Kidney Diseases (NIDDK) and the Juvenile Diabetes Research Foundation (JDRF) for providing human islet for research.

Funding This work was supported by grants from the National Institutes of Health (RO1 DK074970, P50 HD044405), the JDRF (1-2006-837), the March of Dimes Birth Defects Foundation (6-FY07-312) and the American Heart Association (11IRG5570010) to F. Mauvais-Jarvis.

Contribution statement SL and GK performed experiments, analysed data and wrote the manuscript. MSM and GN performed experiments, analysed data and revised the manuscript; YW and JO participated in design of the study and manuscript revision. FMJ conceptualised and designed the study, analysed data and wrote the manuscript. All authors gave approval of the final version of this manuscript for publication.

Duality of interest F. Mauvais-Jarvis has received research support from Pfizer. The remaining authors declare that there is no duality of interest associated with this manuscript.

Open Access This article is distributed under the terms of the Creative Commons Attribution License which permits any use, distribution, and reproduction in any medium, provided the original author(s) and the source are credited.

\section{References}

1. Shapiro AM, Lakey JR, Ryan EA et al (2000) Islet transplantation in seven patients with type 1 diabetes mellitus using a glucocorticoid-free immunosuppressive regimen. N Engl J Med $343: 230-238$ 
2. Hering BJ, Kandaswamy R, Ansite JD et al (2005) Single-donor, marginal-dose islet transplantation in patients with type 1 diabetes. JAMA 293:830-835

3. Shapiro AM, Ricordi C, Hering BJ et al (2006) International trial of the Edmonton protocol for islet transplantation. N Engl J Med 355:1318-1330

4. Robertson RP (2010) Islet transplantation a decade later and strategies for filling a half-full glass. Diabetes 59:1285-1291

5. Weir GC, Bonner-Weir S (2004) Five stages of evolving beta-cell dysfunction during progression to diabetes. Diabetes 53(Suppl 3): S16-S21

6. Davalli AM, Ogawa Y, Ricordi C, Scharp DW, Bonner-Weir S, Weir GC (1995) A selective decrease in the beta cell mass of human islets transplanted into diabetic nude mice. Transplantation 59:817-820

7. Davalli AM, Scaglia L, Zangen DH, Hollister J, Bonner-Weir S, Weir GC (1996) Vulnerability of islets in the immediate posttransplantation period. Dynamic changes in structure and function. Diabetes 45:1161-1167

8. Emamaullee JA, Shapiro AM (2006) Interventional strategies to prevent beta-cell apoptosis in islet transplantation. Diabetes 55:1907-1914

9. Carlsson PO, Palm F, Andersson A, Liss P (2001) Markedly decreased oxygen tension in transplanted rat pancreatic islets irrespective of the implantation site. Diabetes 50:489-495

10. Mattsson G, Jansson L, Carlsson PO (2002) Decreased vascular density in mouse pancreatic islets after transplantation. Diabetes 51:1362-1366

11. Contreras JL, Smyth CA, Bilbao G, Young CJ, Thompson JA, Eckhoff DE (2002) 17beta-Estradiol protects isolated human pancreatic islets against proinflammatory cytokine-induced cell death: molecular mechanisms and islet functionality. Transplantation 74:1252-1259

12. Le May C, Chu K, Hu M et al (2006) Estrogens protect pancreatic beta-cells from apoptosis and prevent insulin-deficient diabetes mellitus in mice. Proc Natl Acad Sci USA 103:9232-9237

13. Liu S, Le May C, Wong WP et al (2009) Importance of extranuclear estrogen receptor-alpha and membrane $\mathrm{G}$ protein-coupled estrogen receptor in pancreatic islet survival. Diabetes 58:2292-2302

14. Wong WP, Tiano JP, Liu S et al (2010) Extranuclear estrogen receptor-alpha stimulates NeuroD1 binding to the insulin promoter and favors insulin synthesis. Proc Natl Acad Sci USA 107:1305713062

15. Liu S, Mauvais-Jarvis F (2010) Minireview: estrogenic protection of beta-cell failure in metabolic diseases. Endocrinology 151:859-864

16. Alonso-Magdalena P, Ropero AB, Carrera MP et al (2008) Pancreatic insulin content regulation by the estrogen receptor ER alpha. PLoS One 3:e2069

17. Tiano JP, Delghingaro-Augusto V, Le May C et al (2011) Estrogen receptor activation reduces lipid synthesis in pancreatic islets and prevents beta cell failure in rodent models of type 2 diabetes. J Clin Invest 121:3331-3342

18. Tiano JP, Mauvais-Jarvis F (2012) Importance of oestrogen receptors to preserve functional beta-cell mass in diabetes. Nat Rev Endocrinol 8:342-351

19. Shifren JL, Tseng JF, Zaloudek CJ et al (1996) Ovarian steroid regulation of vascular endothelial growth factor in the human endometrium: implications for angiogenesis during the menstrual cycle and in the pathogenesis of endometriosis. J Clin Endocrinol Metab 81:3112-3118

20. Mueller MD, Vigne JL, Minchenko A, Lebovic DI, Leitman DC, Taylor RN (2000) Regulation of vascular endothelial growth factor (VEGF) gene transcription by estrogen receptors alpha and beta. Proc Natl Acad Sci USA 97:10972-10977

21. Losordo DW, Isner JM (2001) Estrogen and angiogenesis: a review. Arterioscler Thromb Vasc Biol 21:6-12
22. Morales DE, McGowan KA, Grant DS et al (1995) Estrogen promotes angiogenic activity in human umbilical vein endothelial cells in vitro and in a murine model. Circulation 91:755-763

23. Mendelsohn ME, Karas RH (1999) The protective effects of estrogen on the cardiovascular system. N Engl J Med 340:1801-1811

24. Dupont S, Krust A, Gansmuller A, Dierich A, Chambon P, Mark M (2000) Effect of single and compound knockouts of estrogen receptors alpha (ERalpha) and beta (ERbeta) on mouse reproductive phenotypes. Development 127:4277-4291

25. Molano RD, Pileggi A, Berney T et al (2003) Long-term islet allograft survival in nonobese diabetic mice treated with tacrolimus, rapamycin, and anti-interleukin-2 antibody. Transplantation 75:1812-1819

26. Olsson R, Olerud J, Pettersson U, Carlsson PO (2011) Increased numbers of low-oxygenated pancreatic islets after intraportal islet transplantation. Diabetes 60:2350-2353

27. Chen C, Kuehn C, Bretzel RG, Linn T (2009) Anti-inflammatory thalidomide improves islet grafts survival and functions in a xenogenic environment. PLoS One 4:e6312

28. Armstrong D, Browne R (1994) The analysis of free radicals, lipid peroxides, antioxidant enzymes and compounds related to oxidative stress as applied to the clinical chemistry laboratory. Adv Exp Med Biol 366:43-58

29. Moos WH, Dykens JA, Howell N (2008) $17 \alpha$-Estradiol: a lessfeminizing estrogen. Drug Dev Res 69:177-184

30. Stauffer SR, Coletta CJ, Tedesco R et al (2000) Pyrazole ligands: structure-affinity/activity relationships and estrogen receptor-alpha-selective agonists. J Med Chem 43:49344947

31. Meyers MJ, Sun J, Carlson KE, Marriner GA, Katzenellenbogen BS, Katzenellenbogen JA (2001) Estrogen receptor-beta potencyselective ligands: structure-activity relationship studies of diarylpropionitriles and their acetylene and polar analogues. J Med Chem 44:4230-4251

32. Bologa CG, Revankar CM, Young SM et al (2006) Virtual and biomolecular screening converge on a selective agonist for GPR30. Nat Chem Biol 2:207-212

33. Brissova M, Fowler M, Wiebe $P$ et al (2004) Intraislet endothelial cells contribute to revascularization of transplanted pancreatic islets. Diabetes 53:1318-1325

34. Nyqvist D, Kohler M, Wahlstedt H, Berggren PO (2005) Donor islet endothelial cells participate in formation of functional vessels within pancreatic islet grafts. Diabetes 54:2287-2293

35. Zhang N, Su D, Qu S et al (2006) Sirolimus is associated with reduced islet engraftment and impaired beta-cell function. Diabetes 55:2429-2436

36. Kang L, Zhang X, Xie Y et al (2010) Involvement of estrogen receptor variant ER-alpha36, not GPR30, in nongenomic estrogen signaling. Mol Endocrinol 24:709-721

37. Kuebler JF, Jarrar D, Toth B et al (2002) Estradiol administration improves splanchnic perfusion following trauma-hemorrhage and sepsis. Arch Surg 137:74-79

38. Dobbs R, Sakurai H, Sasaki H et al (1975) Glucagon: role in the hyperglycemia of diabetes mellitus. Science 187:544-547

39. Raskin P, Unger RH (1978) Hyperglucagonemia and its suppression. Importance in the metabolic control of diabetes. N Engl J Med 299:433-436

40. Unger RH, Cherrington AD (2012) Glucagonocentric restructuring of diabetes: a pathophysiologic and therapeutic makeover. J Clin Invest 122:4-12

41. Lee Y, Wang MY, Du XQ, Charron MJ, Unger RH (2011) Glucagon receptor knockout prevents insulin-deficient type 1 diabetes in mice. Diabetes 60:391-397

42. Yu X, Park BH, Wang MY, Wang ZV, Unger RH (2008) Making insulin-deficient type 1 diabetic rodents thrive without insulin. Proc Natl Acad Sci USA 105:14070-14075 
43. Maruyama H, Hisatomi A, Orci L, Grodsky GM, Unger RH (1984) Insulin within islets is a physiologic glucagon release inhibitor. J Clin Invest 74:2296-2299

44. Kawamori D, Kurpad AJ, Hu J et al (2009) Insulin signaling in alpha cells modulates glucagon secretion in vivo. Cell Metabolism 9:350-361

45. Eckhoff DE, Eckstein C, Smyth CA et al (2004) Enhanced isolated pancreatic islet recovery and functionality in rats by $17 \beta$-estradiol treatment of brain death donors. Surgery 136:336-345
46. Ma XL, Gao F, Chen J et al (2001) Endothelial protective and antishock effects of a selective estrogen receptor modulator in rats. Am J Physiol Heart Circ Physiol 280:H876-H884

47. Vacca G, Battaglia A, Grossini E, Mary DA, Molinari C, Surico N (1999) The effect of 17beta-oestradiol on regional blood flow in anaesthetized pigs. J Physiol 514:875-884

48. Salonia A, Lanzi R, Scavini M et al (2006) Sexual function and endocrine profile in fertile women with type 1 diabetes. Diabetes Care 29:312-316 